\title{
Evaluation of cobalt as a performance enhancing drug (PED) in racehorses
}

\author{
K.H. McKeever ${ }^{1 *}$, K. Malinowski ${ }^{1}$, C.K. Fenger ${ }^{2}$, W.C. Duer ${ }^{3}$ and G.A. Maylin ${ }^{4}$ \\ 'Equine Science Center, Department of Animal Science, Rutgers - The State University of New Jersey, New Brunswick, NJ 08901, USA; \\ 2Equine Integrated Medicine, PLC, 4904 Ironworks Rd., Georgetown, KY 40324, USA; ${ }^{3}$ Duer Forensic Toxicology, Inc., Isle Of Sand Key, 1621 \\ Gulf Boulevard, Suite 102, Clearwater, FL 33767, USA; ${ }^{4}$ New York Drug Testing and Research Program, Morrisville State College, Ithaca, NY \\ 14853, USA; mckeever@aesop.rutgers.edu
}

Received: 31 December 2019 / Accepted: 4 February 2020

(c) 2020 Wageningen Academic Publishers

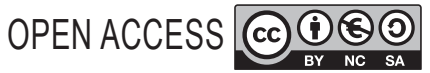

RESEARCH ARTICLE

\begin{abstract}
Cobalt is a required trace element in animals, but administration in excess is considered dangerous and potentially performance enhancing in equine athletes. This study seeks to determine if cobalt may actually act as a performance enhancing drug (PED) by altering biochemical parameters related to red blood cell production as well as markers of aerobic and anaerobic exercise performance. In addition, for adequate regulation of naturally occurring substances, such as cobalt, its distribution among the population must be defined. In order to identify this distribution, plasma Cobalt was determined from 245 Standardbred horses with no cobalt supplementation from farms in New York and New Jersey, including horses at the Rutgers University Equine Science Center. Samples were analysed by Inductively Coupled Plasma Mass Spectrometry. Seven healthy, race fit Standardbreds (4 geldings, 3 mares, age: $5 \pm 3$ years, $~ 500$ $\mathrm{kg}$ ) were used for the PED experiment. An incremental graded exercise test (GXT) to measure maximal aerobic capacity $\left(\mathrm{V}_{2 \max }\right)$ and markers of performance, measurement of plasma volume and blood volume as well as the measurement of lactate, erythropoietin (EPO), and various blood haematological factors were determined 7 days prior to cobalt administration. Each horse was administered a sterile solution of cobalt salts (50 mg of elemental $\mathrm{Co}$ as $\mathrm{CoCl}_{2}$ in $10 \mathrm{ml}$ of saline, IV) at $9 \mathrm{AM}$ on three consecutive days via the jugular vein. Blood samples were obtained from the contralateral jugular vein before and at 1, 2, 4 and $24 \mathrm{~h}$ after administration. Plasma and blood volume were measured one day after the last dose of cobalt, and a post administration GXT was performed the next day. Horses were observed for signs of adverse effects of the cobalt administration (agitation, sweating, increased respiration, etc.). Plasma cobalt concentration increased from a pre-administration mean of $1.6 \pm 0.6$ to $369 \pm 28 \mu \mathrm{g} / \mathrm{l}$ following 3 doses of the cobalt solution $(P<0.05)$. This Co concentration was unaccompanied by changes in aerobic or anaerobic performance, plasma EPO concentration, plasma volume, resting blood volume, total blood volume, or estimated red blood cell volume $(P>0.05)$. There were no observed adverse effects.
\end{abstract}

Keywords: equine, cobalt, performance enhancing drugs

\section{Introduction}

Cobalt (Co, atomic weight 58.9) is a metallic element found throughout nature as a component of soil and ores, typically around $7 \mathrm{mg} / \mathrm{kg}$, but ranging from 1 to $2,500 \mathrm{mg} / \mathrm{kg}$ of soil (https://www.cobaltinstitute.org/cobalt-in-soil.html). It is an essential trace nutrient in all vertebrates, most noteworthy in its role in vitamin B12, which functions as a co-factor in purine synthesis, a key limiting substrate for red blood cell production (Brewer et al., 2016). In addition to its role as a component of B12, Co supports many enzymatic reactions, either as an alternative metal ligand for zinc (Kobayashi and Shimizu, 1999), or as a required metal ligand in pyruvate decarboxylase, an important enzyme in the Kreb's cycle (Jitrapakdee et al., 2008). The recommended daily allowances in humans for cobalt in the form of vitamin B12 is about $0.1 \mu \mathrm{g} /$ day (Unice et al., 2012). The National Research Council, which determines daily requirements of nutrients for animals, has determined a dietary cobalt requirement of 0.5 to $1.1 \mathrm{mg} /$ day in horses and 1.2 to 2.4 $\mathrm{mg} /$ day in cattle, depending upon weight and metabolic state, with intake not to exceed $25 \mathrm{mg} / \mathrm{kg}$ of feed on a dry 
matter basis (Committee on Nutrient Requirements of Horses, 2007). Generally, there is sufficient cobalt in the environment, including soil, water, air and vegetation to support normal body functions in horses (Committee on Nutrient Requirements of Horses, 2007).

Supraphysiologic concentrations of Co result in the stabilisation of an intracellular protein called hypoxia inducible factor (HIF-1 $\alpha$ ), increasing its intracellular concentration. The HIF- $1 \alpha$ protein mediates the response of the animal to low oxygen environments and is constitutively expressed and degraded. During hypoxia or in the presence of HIF stabilisers, these factors are increased in the intracellular environment, resulting in the activation of a cascade of hypoxia-induced gene transcriptions (Benita et al., 2009). Among these effects are the increased transcription and hence plasma concentration of erythropoietin (EPO).

The increase in EPO as a result of increased plasma Co concentration and the resulting increase in red blood cell mass was exploited in human medicine in the 1930s as treatment for anaemia in humans $(25-300 \mathrm{mg} /$ day, Ebert and Jelkmann, 2014). However, the therapeutic index of Co is narrow, with adverse effects possible in every organ system (Faroon et al., 2004), resulting in the rapid replacement of Co therapy by human recombinant erythropoietin (rHuEPO) once it became available in the early 1990's (Brewer et al., 2016). This availability of rHuEPO resulted in its use for performance enhancement in human sports and a concerted effort on the part of regulatory bodies to identify such abuse (Robinson et al., 2006). The rise and then fall of the use of rHuEPO abuse in sports led to a revitalised concern about $\mathrm{Co}$ as a potential blood doping agent (Lippi et al., 2005, 2006).

The effect of increased blood concentrations of Co has been demonstrated in several species, including laboratory animals (Gluhcheva et al., 2011), dogs (Fisher, 1959) and humans (Lippi et al., 2006). The consensus from these crossspecies studies is that chronic blood concentrations in excess of $300 \mu \mathrm{g} / \mathrm{l}$ are required to achieve both haematological and toxicological effects (Finley et al., 2012). However, in horses, no studies examining the administration of sufficient Co to maintain concentrations in excess of $300 \mu \mathrm{g} / \mathrm{l}$ and its effect on athletic performance have been performed. A single IV dose of $49 \mathrm{mg}$ of Co (Knych et al., 2015) achieved Co plasma concentrations in excess of $300 \mu \mathrm{g} / \mathrm{l}$ for only a few hours. Chronic dosing of about $1000 \mathrm{mg}$ of Co (Burns et al., 2018) increased plasma Co concentrations above $300 \mu \mathrm{g} / \mathrm{l}$ for 50 days, and chronic dosing over 35 days with doses that failed to achieve the $300 \mathrm{ng} / \mathrm{ml}$ level (Wenzel et al., 2019) have also been performed. None of these studies demonstrated any effect on red blood cell parameters in the experimental horses, and none of these studies investigated effects of
Co on exercise. Therefore, this study was performed to test the hypothesis that cobalt administration sufficient to raise plasma Co above $300 \mathrm{ng} / \mathrm{ml}$ would alter biochemical parameters related to red blood cell production and markers of exercise performance.

\section{Materials and methods}

\section{Population survey of horses known not to have been administered cobalt (experiment 1)}

\section{Animals}

The horses sampled for this population study included 245 Standardbred horses that were at farms throughout New York and New Jersey, including horses at the Rutgers University Equine Science Center. All of the horses were dewormed and vaccinated per standard veterinary practice. The horses sampled had received no supplementation either by intravenous or oral routes, other than the cobalt in the complete pelleted ration or hay. Blood samples $(20 \mathrm{ml})$ were drawn using the Vacutainer collection system into tubes containing EDTA (Vacutainer, Becton Dickinson, Inc, Franklin Lakes, NJ, USA) and immediately placed on ice. Tubes were shipped on ice to the New York Drug Testing and Research Program, centrifuged and the plasma transferred to cryovials stored at $-80^{\circ} \mathrm{C}$ for batch analysis of cobalt concentration.

\section{Cobalt analysis}

Negative controls and samples were prepared by adding $4.9 \mathrm{ml}$ of $1 \% \mathrm{w} / \mathrm{v} \mathrm{HNO}_{3}$ to a $15 \mathrm{ml}$ plastic centrifuge tube. A $0.1 \mathrm{ml}$ aliquot of sample was added and samples were vortexed for $10 \mathrm{~s}$ before transferring to auto sampler vials. Spikes were prepared in an identical manner but with the addition of $5 \mu \mathrm{l}$ of $1000 \mathrm{mg} / \mathrm{l} \mathrm{Co} \mathrm{spike} \mathrm{solution.} \mathrm{Calibration}$ and internal standards (were prepared in $1 \% \mathrm{w} / \mathrm{v} \mathrm{HNO}_{3}$. Samples were analysed using a 6 level calibration consisting of $0,0.001,0.01,0.1,10$, and $100 \mu \mathrm{g} / \mathrm{l}$ standards with a 1 $\mu \mathrm{g} / \mathrm{l}$ check sample. A calibration curve was prepared by serial dilution starting with $1000 \mu \mathrm{g} / \mathrm{l}$ and diluting each subsequent sample $10 \times$ until a concentration of 0.001 $\mu \mathrm{g} / \mathrm{l}$ was reached. The $1 \mu \mathrm{g} / \mathrm{l}$ sample was used to verify the calibration along with an independently prepared $1 \mu \mathrm{g} / \mathrm{l}$ check sample. Five calibration blanks were tested prior to calibration to eliminate any possible blank contamination. Prior to analysis the instrument was allowed to warm-up per the manufacturer's recommendation and a semi auto tune was performed. A typical run included: calibration, calibration blank verification, calibration verification, calibration check, negative control and spike samples that were analysed before and after the samples. Check samples were run every 20 samples and internal standard was added online. 
Samples were analysed using an Agilent 8800 ICP-MS Triple Quad in MS/MS mode with helium cell gas $(4.3 \mathrm{ml} / \mathrm{min})$ (Agilent, Santa Clara, CA, USA). Nickel sampler and skimmer cones along with a MicroMist nebulizer (Glass Expansion, Pocasset, MA, USA), quartz spray chamber and quartz torch were used for analysis. The forward power was set at 1,550 W, sampling depth at $8 \mathrm{~mm}$, carrier gas at $1.00 \mathrm{l} / \mathrm{min}$, and makeup/dilution gas at $0.10 \mathrm{l} / \mathrm{min}$. Data was analysed using MassHunter software (Agilent). Trace metal grade reagents were used when available otherwise high purity reagents were used. The internal calibration standard mix contained $\mathrm{Bi}, \mathrm{Ge}, \mathrm{ln}, \mathrm{Li}(6), \mathrm{Sc}, \mathrm{Tb}$, and $\mathrm{Y}$, each at $10 \mathrm{mg} / \mathrm{l}$ (Part \#5183-4681, Agilent). Ge was used as the internal standard for cobalt due to similar atomic mass and first ionization potential. A $10,000 \mathrm{mg} / \mathrm{l}$ Co standard (Part \#5190-8376, Agilent) and was used to prepare all calibration samples, calibration verifications, calibration checks, and spikes. Precision was determined by analysing twenty $50 \mu \mathrm{g} / \mathrm{l}$ spikes. Intra-day accuracy was determined by analysing 28 samples at $50 \mu \mathrm{g} / \mathrm{l}$, and inter-day accuracy was determined by preparing analysing 15 samples at $50 \mu \mathrm{g} / \mathrm{l}$ on three different days independently prepared by several analysts. Accuracy was also determined by measurements in duplicate on 20 different days at $1 \mu \mathrm{g} / \mathrm{l}$. The limit of detection (LOD), was 3 times the background signal, which was mean $+3 \times \mathrm{SD}$ of $20 \mathrm{HNO}_{3}$ blank samples. The limit of quantitation (LOQ) was 10 times the background signal.

\section{Statistical analysis}

The mean, median, standard deviation and skewness of the population data set were determined using MS Excel 2010 (Microsoft, Redmond, WA, USA), while visual inspection of the histograms was used to estimate the mode. Thresholds were determined using different calculation techniques: inequality formulas derived from Cramer (1946), formulas for the non-central t distribution or 95/95 tolerance interval method (Hahn and Meeker, 1991), loglogistic and exponential data fitting (Campbell, 1988). The goodness of fit of each distribution was determined using XLSTAT $\odot$ (Addinsoft Inc, New York, NY, USA) at alpha level of $P<0.05$. A 1 in 10,000 threshold was determined for each of these methods, other than the 95/95 tolerance.

\section{Performance study (experiment 2)}

\section{Animals and cobalt administration}

Seven healthy, race fit Standardbreds (4 geldings, 3 mares, age: $5 \pm 3$ years, $\sim 500 \mathrm{~kg}$ ) were used for this experiment. Every horse was acclimated to the Rutgers University Equine Exercise Physiology Lab personnel, housing, and training equipment in the two months prior to the start of the experiment. Animals were fed a maintenance ration $(\sim 1 \%$ of body mass) of alfalfa/grass hay ad libitum $(\sim 6 \mathrm{~kg} / \mathrm{d})$ and a high-protein (14\% crude protein) pelleted grain concentrate ( $\sim 3 \mathrm{~kg} / \mathrm{d}$; 14\% Ultra Horse Pellet Brown's Feed, Birdsboro, PA, USA) throughout the study period (digestible energy $\sim 17$ Mcals/d). Water and mineral blocks were also provided ad libitum. The horses were housed, by sex, in groups of four per two-acre dry lot paddock. The Rutgers University Institutional Animal Care Review Board approved all methods and procedures used in this experiment.

Before receiving any Co treatment, all animals completed a series of baseline testing. This included an incremental graded exercise test (GXT) to measure maximal aerobic capacity $\left(\dot{\mathrm{VO}}_{2 \max }\right)$ and other markers of performance, plasma volume, blood volume, lactate, EPO and haematological parameters. Administration of cobalt salts commenced seven days after the pre-dosing GXT. Each horse was administered a sterile solution of cobalt salts (50 mg of elemental $\mathrm{Co}$ as $\mathrm{CoCl}$ in $10 \mathrm{ml}$ of saline, IV) at 9 AM on three consecutive days. The drug was administered via the jugular vein. Blood samples were obtained from the contralateral jugular vein before and at 1, 2, 4 and $24 \mathrm{~h}$ after administration. Plasma and blood volume were measured one day after the last dose of cobalt. This was followed by a post-administration GXT that was performed the next day.

\section{Graded exercise test}

This test was designed to measure $\dot{\mathrm{VO}}_{2 \max }$ and several indices of exercise performance (Kearns and McKeever, 2002; McKeever et al., 2006). Prior to the test, the horses were weighed and a catheter (Angiocath, 14 gauge, Becton Dickinson, Inc.) inserted percutaneously into the left jugular vein using sterile techniques and local lidocaine anaesthesia. The horses were then allowed to stand quietly for an equilibration period of approximately 10-15 min. The horses were walked onto the treadmill where standing gas exchange data, and a baseline blood sample $(40 \mathrm{ml})$ were obtained prior to performing the GXT. The GXT was comprised of a run on a high speed horse treadmill (Sato I, Equine Dynamics, Inc., Lexington, KY, USA) at a fixed $6 \%$ grade while wearing the indirect open-flow calorimeter apparatus (Oxymax-XL, Columbus Instruments, Inc. Columbus, OH, USA) used to measure oxygen uptake. The GXT started at an initial speed of $4 \mathrm{~m} / \mathrm{s}$ for one min which was increased to $6 \mathrm{~m} / \mathrm{s}$ followed by $1 \mathrm{~m} / \mathrm{s}$ incremental increases every $60 \mathrm{~s}$ until the horses reached fatigue. Fatigue was defined as the point where the horse could not keep up with the treadmill despite humane encouragement. After this, the treadmill was stopped and 5 min of post-exercise calorimetry data collected. Oxygen uptake was measured continuously during the test and recorded at $10 \mathrm{~s}$ intervals using the open flow calorimetry system (Oxymax-XL). 
Blood chemistry

Blood samples were obtained for packed cell volume (PCV), total protein, plasma lactate concentration, and plasma EPO. Packed cell volume was determined during the GXT at -30 min and immediately before exercise, during the last $10 \mathrm{~s}$ of each increment of the test, and each day before and 1,2 , and $4 \mathrm{~h}$ after Co administration. Plasma lactate was determined during the GXT at -30 min and immediately before exercise, during the last $10 \mathrm{~s}$ of each increment of the test. Plasma EPO was determined GXT at -30 min and immediately before exercise and immediately post-exercise. Blood samples were immediately transferred into pre-chilled tubes containing EDTA and lithium heparin (Vacutainer, Becton Dickinson, Inc.) and placed on ice. Plasma for the measurement of lactate and hormones were separated and stored at $-80{ }^{\circ} \mathrm{C}$ for batch analysis. Plasma lactate concentrations were measured in duplicate using a blood chemistry analyser (ABL Flex 880; Radiometer, Copenhagen, Denmark). Packed cell volume and plasma protein were measured in duplicate using the microhematocrit technique and refractometry. Plasma EPO was measured in duplicate using a commercially available enzyme-linked immunosorbent assay. Cobalt concentrations were determined using inductively coupled plasma tandem mass spectrometry (ICP MS/MS).

\section{Plasma volume and blood volume}

Resting plasma volumes (PV) were measured using a modified Evans blue dye dilution method (Kearns and McKeever, 2002; McKeever et al., 2010a). Resting circulating blood volume $\left(\mathrm{BV}_{\text {rest }}\right)$ was calculated using $\mathrm{PV}$, the haematocrit (HCT) measured at rest, and standard calculations (McKeever et al., 1987, 1988; Rose and Hodgson, 1994; Persson, 1967). Estimated total blood volume (tBV) was calculated using the same formula for BV but with the HCT obtained at the $7 \mathrm{~m} / \mathrm{s}$ step of the incremental exercise test (Persson, 1967; Rose and Hodgson, 1994). This volume provides an estimate of total blood volume as exercise induced fluid shifts influence PCV (McKeever et al., 2010a). The estimated red blood cell volume (eRCV) was determined by tBV minus the measured PV. All measures besides tBV were made while the horses were standing quietly (at rest) in their respective stalls two days prior to the pre-cobalt administration GXT and two days before the post administration GXT.

\section{Statistical analysis}

Results were expressed as means \pm standard error of the mean (SEM). Data were tested for normality using ShapiroWilks and Kolmogorov-Smirnov with Lilliefors correction (SigmaStat v. 4.0, Systat Inc., San Jose, CA, USA) before comparison by group and time using two-way ANOVA for repeated measures. Comparisons of data before and after treatment utilised a t-Test for paired comparisons. The $a$ priori level of statistical significance set at $P<0.05$.

\section{Results}

The validation of the method employed for the analysis of cobalt contained a calibration curve of 0, 0.001, 0.01, 0.1, 10 , and $100 \mu \mathrm{g} / \mathrm{l} \mathrm{Co}$. The response was linear and gave correlation coefficients $\left(\mathrm{R}^{2}\right)$ of 0.99 or better. Inter-day precision (\% relative standard deviation) at $50 \mu \mathrm{g} / \mathrm{l}$ was $6.5 \%$, intra-day precision (\% relative standard deviation) was $3.6 \%$, and precision at $1 \mu \mathrm{g} / \mathrm{l}$ was $4.4 \%$. Inter-day accuracy at $50 \mu \mathrm{g} / \mathrm{l}$ (\% nominal concentration) was $102.0 \%$, intra-day accuracy at $50 \mu \mathrm{g} / \mathrm{l}$ (\% nominal concentration) was $96.4 \%$, and Inter-day accuracy at $1 \mu \mathrm{g} / \mathrm{l}$ (\% nominal concentration) was $100.78 \%$. The LOD was $0.01 \mu \mathrm{g} / \mathrm{l}$, and the LOQ was $0.03 \mu \mathrm{g} / \mathrm{l}$.

\section{Population survey (experiment 1)}

The data are summarised in Table 1. Log-logistic and exponential curve fits are shown in Figure 1, in which the data have been analysed using the @Risk software and Cramer calculated thresholds. The best fit for the data is represented by the log-logistic curve produced with @Risk software (Figure 1A), although neither the log-logistic nor the exponential curves described the data when tested for goodness of fit at alpha $P<0.05$. The curve fitting (Figure 1 ) and thresholds (Table 1) are shown for demonstration purposes, although only the Cramer threshold is appropriate for use for these data.

Table 1. Statistical moments and calculated plasma cobalt (Co) thresholds $(\mu \mathrm{g} / \mathrm{l})$ for the population study $(n=245)$.

$\begin{array}{lc}\text { Median } & 0.76 \\ \text { Mode } & 0.65 \\ \text { Mean } & 1.03 \\ \text { Standard deviation (SD) } & 0.92 \\ \text { Skewness } & 4.18 \\ \text { Sample size } & 245 \\ \text { Cramer threshold }(1 \text { in } 10,000) & 68.0 \\ \text { Parametric } 95 / 95 \text { tolerance }(\sim 1 \text { in } 20) & 3.53 \\ \text { Log-logistic fit }(1 \text { in } 10,000) & 71.12 \\ \text { Exponential fit }(1 \text { in } 10,000) & 14.83\end{array}$


A Log-logistic

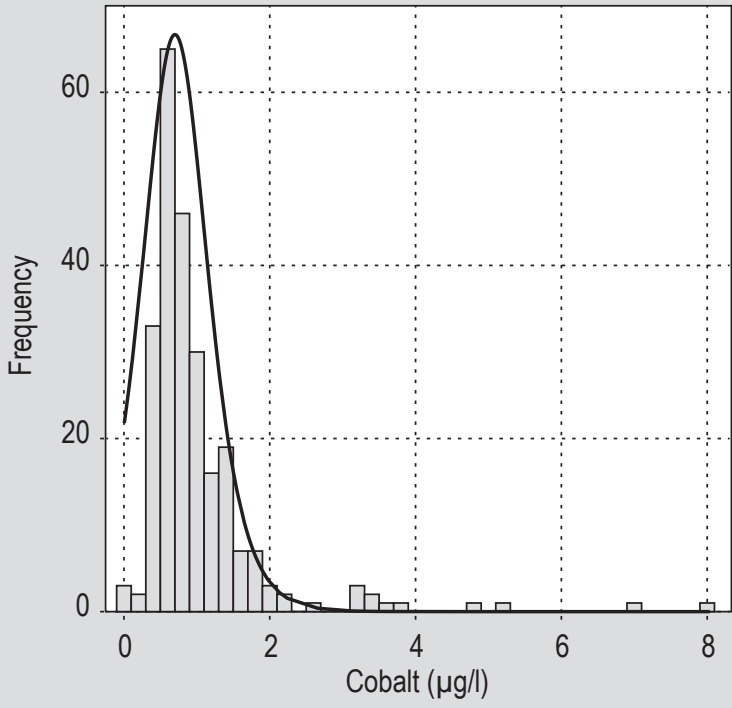

B Exponential

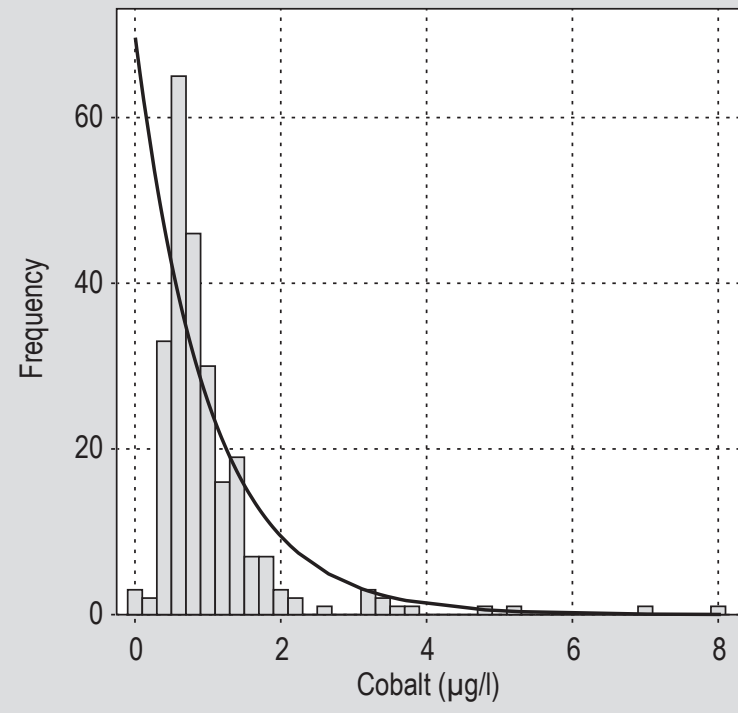

Figure 1. Frequency histogram overlaid by defined distributions fit for cobalt plasma concentrations among 245 Standardbreds. (A) Log-logistic distribution and (B) exponential distribution. Neither distribution fits the underlying data $(P>0.05)$, but the loglogistic distribution appears closest on a visual basis.

\section{Effect of cobalt on exercise performance (experiment 2)}

Three days of cobalt administration increased $(P<0.05)$ plasma cobalt concentration from a pre-administration mean of $1.6 \pm 0.6$ to $369 \pm 28 \mu \mathrm{g} / \mathrm{l}$ following 3 doses of the cobalt solution (Figure 2$)$. There were no changes $(P>0.05)$ in biomarkers, markers of aerobic and anaerobic performance (Figures 3 and 4), nor were that any changes $(P>0.05)$ in plasma EPO concentration (Figure 5), packed cell volume (Figure 6), total protein (data not shown), plasma volume, resting blood volume, total blood volume, or estimated red blood cell volume (Table 2). There were no observed adverse effects.

\section{Discussion}

One of the most important contributors to successful athletic competition, whether it is professional cycling or horse racing is the oxygen carrying capacity of the blood (Mairbäurl, 2013). The illicit manipulation of red blood cell mass by infusion of actual blood or blood products, called blood boosting, or blood doping using $\mathrm{rHuEPO}$ are well documented in human sports. Studies have shown that the benefits to athletic performance from this artificial increase in red blood cell mass are seen as both increases in velocity and time to exhaustion in humans (Jelkmann and Lundby, 2011) and improvement in velocity at $\mathrm{VO}_{2 \max }$
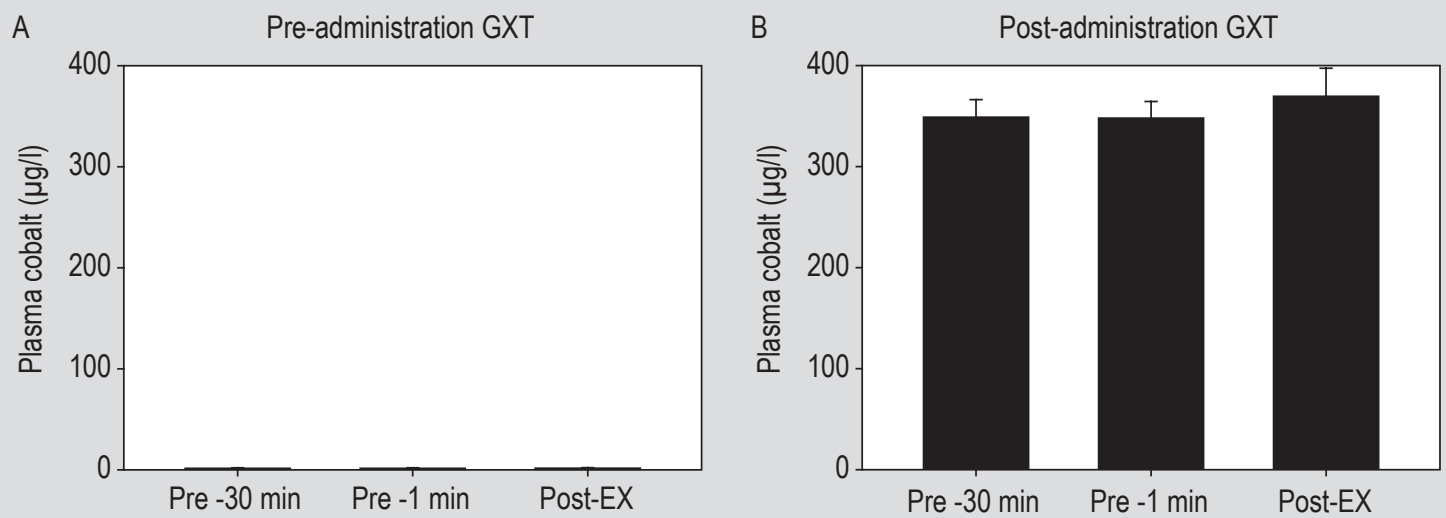

Figure 2. Mean \pm standard error cobalt (Co) concentrations in samples collected before and after the standardised graded exercise tests (GXT) performed 7 days before Co administration and $24 \mathrm{~h}$ after 3 consecutive days of administration of a solution of cobalt salts. 

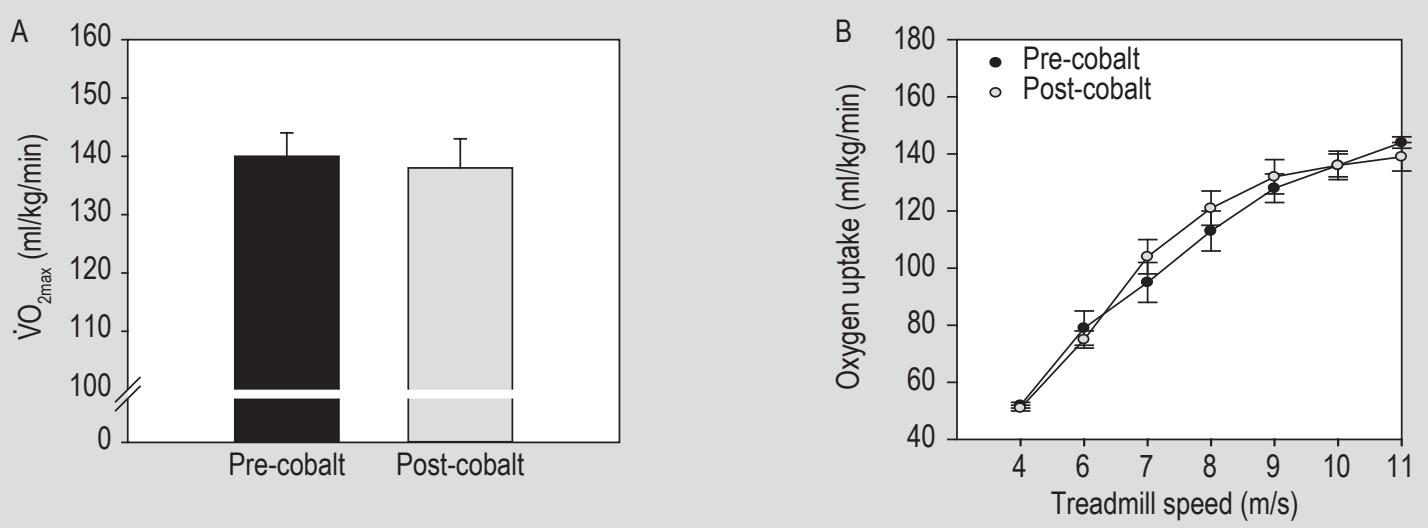

Figure 3. Effect of cobalt (Co) administration on (A) maximal aerobic capacity $\left(\mathrm{V}_{2 \max }\right)$ and $(\mathrm{B})$ submaximal rate of oxygen consumption. Pre-cobalt is data from a standardised graded exercise test (GXT) 7 days before $\mathrm{Co}$ administration and post-cobalt is from GXT $24 \mathrm{~h}$ after the last of 3 consecutive days of $\mathrm{Co}$ administration. There was no significant effect on either exercise parameter.

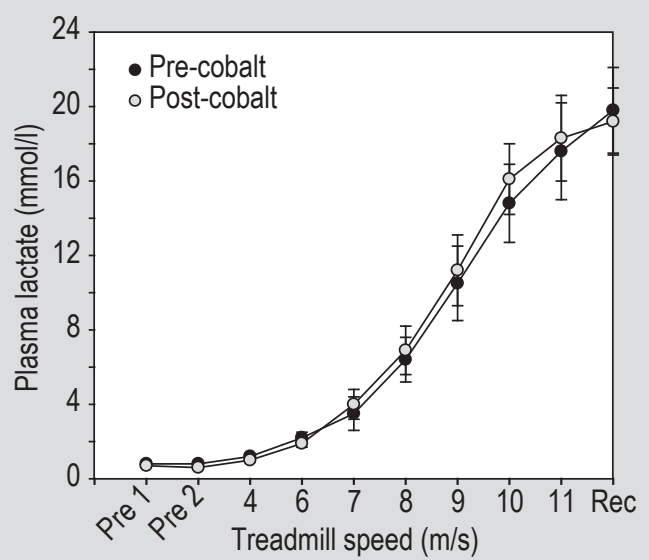

Figure 4. Plasma lactate concentrations (LA) measured during the 7-day pre-administration standardised graded exercise test (GXT)and the $24 \mathrm{~h}$ post-administration GXT. There was no effect $(P>0.05)$ of cobalt administration on the lactate response to exercise.

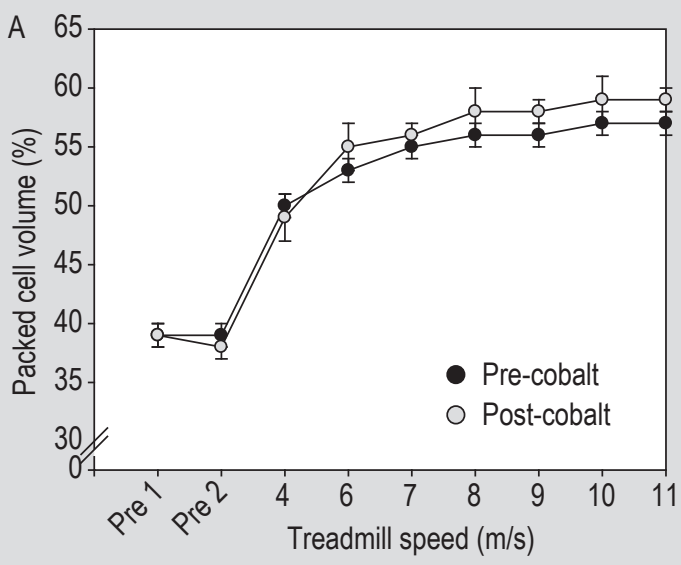

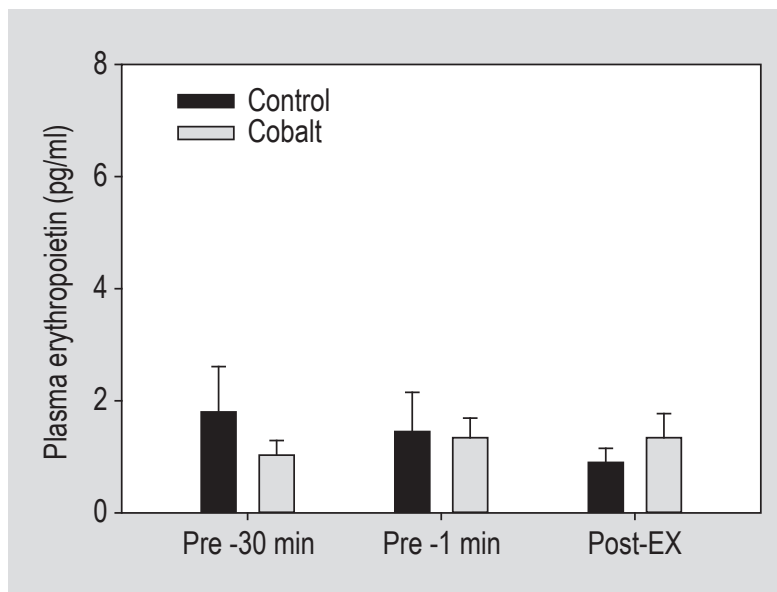

Figure 5. Plasma erythropoietin concentrations (EPO) measured before and after the 7-day pre-administration standardised graded exercise test (GXT) and the $24 \mathrm{~h}$ post final Co postadministration GXT. There were no effects $(P>0.05)$ of either exercise or cobalt administration on plasma EPO.

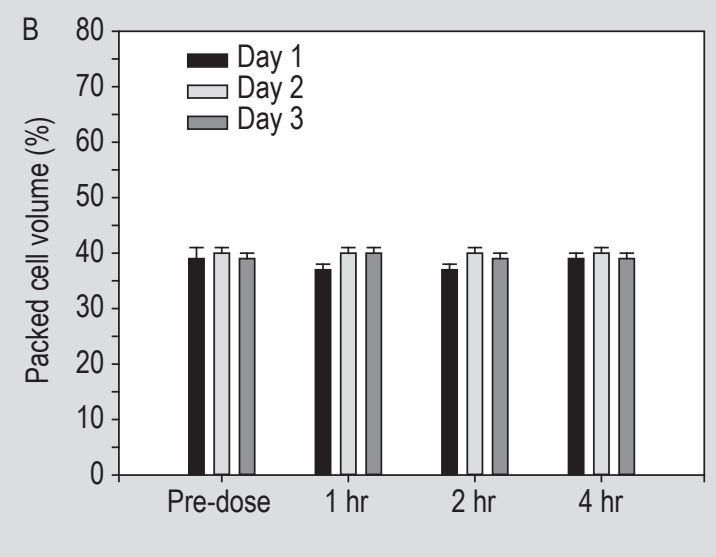

Figure 6. The effect of cobalt (Co) administration on packed cell volume (PCV, mean \pm standard error). (A) The increase in PCV owing to the normal addition of red blood cells into the central circulation due to splenic reserve mobilisation is demonstrated in both standardised graded exercise test (GXT), with no effect of Co administration. (B) The PCV measured before and 1, 2 and $3 \mathrm{~h}$ after the administration of each dose of cobalt. There was no significant effect of dose administration. 
Table 2. Vascular volumes ( $\mathrm{ml}$ ) before and three days after cobalt administration: Plasma volume (PV), blood volume at rest (BVrest), total blood volume (BVtot), estimated red blood cell volume (eRCV).

$\begin{array}{lllll} & \text { PV } & \text { BV }_{\text {rest }} & \text { BV }_{\text {tot }} & \text { eRCV } \\ \text { Pre-cobalt administration (Mean } \pm \text { standard error) } & & & & \\ \text { Post-cobalt administration (Mean } \pm \text { standard error) } & 15,208 \pm 116 & 23,587 \pm 477 & 30,690 \pm 814 & 15,483 \pm 792 \\ \text { P-value } & 15,315 \pm 118 & 23,375 \pm 436 & 30,847 \pm 779 & 15,591 \pm 725 \\ \text { (n) } & 0.61 & 0.72 & 0.39 & 0.42\end{array}$

in equines (McKeever et al., 2006). Owing to the advent of biological passports and advanced testing methods, these doping methods have become more difficult for human athletes to use without detection (Jelkmann and Lundby, 2011). This increased vigilance of regulatory agencies has led to the conjecture that alternatives may be employed by athletes for the same purpose, particularly cobalt, the original treatment used to increase human haematocrits in the treatment of anaemia (Lippi et al., 2005). This suspicion is supported by the large variety of sports supplements in the market that contain cobalt well above the human recommended daily allowance of cobalt, either on the label, or undeclared (Thevis et al., 2016). Testing surveys among racing horses has similarly supported that such use of Co in excess of recommended dietary requirements has also been in place in equine sports (Brewer et al., 2016).

The daily requirements of dietary cobalt in horses is a modest 0.5 to $1.1 \mathrm{mg} /$ day although they can tolerate as much as $25 \mathrm{mg} / \mathrm{kg}$ of feed on a dry matter basis, which could be as high as $225 \mathrm{mg}$ of Co per day (Committee on Nutrient Requirements of Horses, 2007). This disparity between what is required and what is tolerated is likely adaptation because of the wide variation of cobalt in soils upon which feedstuffs and hay are grown. There are Co deficient regions such as New England, Michigan and coastal regions of the South-eastern United States (Kubota et al., 1987) and Co contaminated soils as a consequence of mining, smelting and spreading of sludge (Zabrowska et al., 2016). Consequently, before a naturally occurring substance, such as Co can be successfully regulated, its distribution must be determined among the population of interest.

Ho et al. (2015) used a population survey of 7,462 Hong Kong post-race urine samples to determine the distribution of Co in the population of interest, and used a log-normal distribution to determine a urinary threshold for Co of 75 ppb. Curiously, the distribution of the Ho et al. (2015) data was considered to be log-normal based on a KolmogorovSmirnov test with a $P=0.05$, which, although close to significance, does not meet the $P>0.05$ requirement of the normality test employed. The more appropriate test would include a Lillifors correction, because KolmogorovSmirnov lacks sensitivity when the data contain a long tail
(R core team, 2014), such as is observed with Co datasets. Further, as the samples used were post-race samples, the entire dataset is a sample of convenience rather than a known sample of horses unsupplemented with Co. While the authors claim that the $75 \mu \mathrm{g} / \mathrm{l}$ urine threshold provides a 1 in 10,315 risk of a false positive test, this would only be true if the underlying distribution were truly lognormal, an assumption that is in question based upon the Kolmogorov-Smirnov normality test employed. The use of urine regulatory thresholds for Co have also been brought into question by a recent study by Wenzel et al. (2019), who determined that high urine Co concentrations were most effective at determining an acute Co exposure, rather than Co misuse.

Plasma Co concentrations were also investigated by Ho et al. (2015), using 375 Hong Kong post-race plasma samples. Using the Kolmogorov-Smirnov normality test, also without the Lilliefors correction, the data were considered to be normally distributed, without transformation, at $P=0.068$. Additionally, the authors then used a calculation of mean $+3.72 \mathrm{SD}$. to achieve a threshold of $1.14 \mu \mathrm{g} / \mathrm{l}$, rounded up to $2.0 \mu \mathrm{g} / \mathrm{l}$ and called that a risk of 1 in quadrillion of a false positive test. Similar to the urine findings, these were post-race samples, rather than horses with a known dietary and medication history, and the risk of a false positive would only be accurate if the distribution were truly normal. More interesting is that when 109 post-race samples from the Emirates Racing Authority were tested, 6 samples had to be eliminated as high outliers and the resulting data required a square root transformation to achieve a similarly questionable normal distribution using the Kolmogorov-Smirnov without the Lillefors correction. Either neither distribution, the normal or square root transform, correctly reflects the plasma Co concentration of horses, or Co may be expected to follow a different distribution depending upon geographic region. Clearly the use of post-race samples to determine a distribution of plasma Co concentrations without prior knowledge of the dietary and/or medication history of the underlying horses in the sample is inappropriate. Equally inappropriate is the application of different data transformation to different data sets of the same parameter in order to achieve a normal distribution, and eliminating outliers without careful investigation as to their source. 
Our study sought to describe the distribution of plasma Co concentrations in horses under a controlled environment without prior excessive Co administration and establish a threshold using multiple methods, including the commonly applied 95/95 tolerance, curve fitting and the distribution free Cramer inequality. Our data demonstrate the importance of investigating multiple methodologies to calculate regulatory thresholds and determining the best fit. Previous studies have demonstrated the potentially wide variation between calculated thresholds depending upon the method employed, particularly where the required assumptions for the method fail to be met (Machin et al., 2019). Similar to the Ho et al. (2015) data, our data could not be fit to typical distributions, including exponential, $\log$-logistic or the non-central T-distributions. Figure 1 shows that the log-logistic distribution, although failing to pass the goodness of fit test at $P<0.05$, is visually a very close fit to the plasma Co concentrations in our population. The Cramer distribution-free inequality method of determining a threshold requires no distribution fitting, and was very close to the threshold determined using the log-logistic distribution. The fact that the threshold calculated from the curve with the closest fit and the distribution free inequality are very similar indicate that a threshold close to $70 \mu \mathrm{g} / \mathrm{l}$ is likely the most appropriate threshold to represent a 1 in 10,000 risk of a false positive for a racing population.

Despite the common addition of Co to both oral supplements and intravenous formulations administered to horse in excess of their requirements, studies to date have failed to demonstrate any effect of Co on EPO or any haematological parameters in horses. A single IV dose of $49 \mathrm{mg}$ of Co (Knych et al., 2015) which resulted in serum concentrations of Co over $300 \mu \mathrm{g} / \mathrm{l}$ for only a few hours had no effect on EPO concentrations, any haematological parameters or heart rate in any horses. Four weekly administrations of up to about $1000 \mathrm{mg}$ of Co (Burns et al., 2018) similarly failed to impact EPO concentrations or haematological concentrations, although profound acute behavioural effects immediately after administration that were attributed to anxiety and colic were identified. In the highest two dose groups, $4 \mathrm{mg} / \mathrm{kg} \mathrm{CoCl}(2.4 \mathrm{mg} /$ $\mathrm{kg} \mathrm{Co})$ and $2 \mathrm{mg} / \mathrm{kg} \mathrm{CoCl}(1.2 \mathrm{mg} / \mathrm{kg} \mathrm{Co})$ administered weekly for four weeks, horses exceeded the $300 \mu \mathrm{g} / \mathrm{l}$ plasma level for over 50 days, and showed no changes in EPO or haematological effects (Burns et al., 2018). A similar study of chronic Co at doses as high as $25 \mathrm{mg}$ twice weekly over a 42-day period failed to exert any effect on haematocrit of horses, although this dosing regimen also failed to achieve $300 \mu \mathrm{g} / \mathrm{l}$ concentration in plasma (Wenzel et al., 2019). Our findings are in agreement with the existing literature that, despite the evidence in other species that persistent plasma Co concentrations above $300 \mu \mathrm{g} / \mathrm{l}$ result in EPO and haematological effects, no such effect is observed in horses.
This finding that horses are unique in their failure to respond to Co may relate to other adaptations of this species that are fairly unique in the animal kingdom. The utilisation of oxygen is roughly equivalent to the ability of the organism to perform work, and the limiting factor in oxygen utilisation is oxygen delivery (Levine, 2008). Horses have an exceptionally high capacity to utilise oxygen, and move their blood volume across the pulmonary circulation, a feature accompanied by a marked exercise induced arterial hypoxemia (Fenger et al., 2000). Additionally, horses store one third to one half of their red blood cell mass in their spleen, which likely contributes to their high aerobic capacity (McKeever et al., 2010b). Horses also fail to respond to a move to altitude with a sustained EPO response, such as is seen in other species (McKeever et al., 2010b). We did not measure HIF in this study, but horses with heaves are able to respond to hypoxia with an increase in HIF (Toussaint et al., 2012), and equine dermal cells are able to respond to Co with an increase in HIF (Deschene et al., 2012), so it is likely that the lack of an EPO response to Co shown in other studies and confirmed here is related to an attenuated response of the horse to HIF rather than a lack of HIF response. This muted response is likely an adaptive response to protect against polycythaemia in the face of hypoxemia, since hypoxemia is commonly encountered by the equine.

Exercise effects have been demonstrated with Co supplementation in other species. In rats, Co supplementation improved aerobic performance at a daily dose of $10 \mathrm{mg} / \mathrm{kg}$, increasing the time to exhaustion in a swimming test, decreased the amount of muscle damage and decreased the oxidative stress within muscle, in addition to the expected effect of increasing haemoglobin and haematocrit (Saxena et al., 2010). In the rats, $10 \mathrm{mg} / \mathrm{kg}$ was determined to be the minimal effective dose of Co. In humans, no effect on performance parameters was observed with a much more conservative dose of $5 \mathrm{mg}(\sim 0.07 \mathrm{mg} /$ $\mathrm{kg}$ ) orally daily for 3 weeks, although the authors indicate that small improvements may not have been detectable using their experimental protocol (Hoffmeister et al., 2018). Our study shows no effect on any performance parameters in horses after daily Co administration with $50 \mathrm{mg}$ for 3 days, sufficient to increase plasma Co concentrations above $300 \mu \mathrm{g} / \mathrm{l}$.

In summary, this study answers two important questions regarding the effects of Co on horses. First, we describe the plasma Co distribution in a population of horses on a maintenance dietary ration without excessive Co supplementation. Previous surveys included only postrace samples from horses with unknown dietary and supplement histories. Our survey included only horses with known dietary histories. Further, previous studies applied parametric statistical methods, although their data did not clearly conform to the requirement of normality. We 
used curve-fitting and a distribution free method to obtain best fit and calculate an appropriate threshold from these methods. The log-logistic curve fit and Cramer (distribution free) were in good agreement with a threshold of 68 to 71 $\mu \mathrm{g} / \mathrm{l}$ for this Co supplemented population. In the second component of the study, we investigated the effect of a Co dose sufficient to maintain plasma levels over $300 \mu \mathrm{g} / \mathrm{l}$ on performance and found no effect on indices of either aerobic or anaerobic performance. In conclusion, a threshold of $25 \mu \mathrm{g} / \mathrm{l}$ in plasma, in place in many jurisdictions, may result in horses exceeding the threshold without excessive Co administration. Further, raising the threshold to our suggested $71 \mu \mathrm{g} / \mathrm{l}$ would not jeopardise the integrity of racing, as there would be no effect on performance, nor any animal welfare concerns at this plasma concentration.

\section{Acknowledgements}

The authors would like to thank the United States Trotting Association, the Rutgers Equine Science Center, the New Jersey Agricultural Experiment Station, and the New York Drug Testing and Research Program for the funding that supported this project. The authors also express gratitude to the Fair Winds Farm; Concord Stud Farm, the Standardbred Retirement Foundation, Heritage Hill Farm, and Gale's Way Farm for providing the horses used for the project. Many thanks to Dylan Klein, Ali Janabi, Kate Goodman and all the students who assisted in conducting the experiments. Finally, we thank all of the horses for their participation.

\section{References}

Benita, Y., Kikuchi, H., Smith, H.D., Zhang, M.Q., Chung, D.C. and Xavier, R.J., 2009. An integrative genomics approach identifies hypoxia inducible factor-1 (HIF-1)-target genes that form the core response to hypoxia. Nucleic Acids 37: 4587-4602. https://doi. org/10.1093/nar/gkp425

Brewer, K., Maylin, G.A., Fenger, C.K., Tobin, T., 2016. Cobalt use and regulation in horseracing: a review. Comparative Exercise Physiology 12: 1-10.

Burns, T.A., Dembek, K.A., Kamr, A., Dooley, S.B., Dunbar, L.K., Aarnes, T.K., Bednarski, L.S., O’Brien, C., Lakritz, J., Byrum, B., Wade, A., Farmer, R., Tan, S. and Toribio, R.E., 2018. Effect of intravenous administration of cobalt chloride to horses on clinical and hemodynamic variables. Journal of Veterinary Internal Medicine 32: 441-449. https://doi.org/10.1111/jvim.15029

Campbell, M.J., 1988. Calculating confidence intervals for some nonparametric analyses. Statistics in Medicine 296: 1454-1456.

Committee on Nutrient Requirements of Horses, 2007. Minerals. In: Lawrence, L., Cymbaluk, N.F., Freeman, D.W., Geor, R.J., GrahamThiers, P.M., Longland, A.C., Nielsen, B.D., Siciliano, P.D., Topliff, D.R., Valdes, E.V. and Van Saun, R.J. (eds.) Nutrient requirements of horses, $6^{\text {th }}$ ed. The National Academies Press, Washington, DC, USA.

Cramér, H., 1946. Mathematical methods of statistics. Princeton University Press, Princeton, NJ, USA.
Deschene, K., Céleste, C., Boerboom, D. and Theoret, C.L., 2012. Hypoxia regulates the expression of extracellular matrix associated proteins in equine dermal fibroblasts via HIF1. Journal of Dermatological Science 65: 12-18.

Ebert, B. and Jelkmann, W., 2014. Intolerability of cobalt salt as erythropoietic agent. Drug Testing and Analysis 6: 185-189. https:// doi.org/10.1002/dta.1528

Faroon, O.M., Abadin, H., Keith, S., Osier, M., Chappell, L.L., Diamond, G. and Sage, G., 2004. Health effects. In: Toxicological profile for cobalt. Agency for Toxic Substances and Disease Registry, United States Department of Health and Human Services, Atlanta, GA, USA, pp. 27-86. Available at: https://www.atsdr.cdc.gov/ToxProfiles/ tp33.pdf

Fenger, C.F., McKeever, K.H., Hinchcliff, K.W. and Kohn, C.W., 2000. Determinants of oxygen delivery and hemoglobin saturation during incremental exercise in horses. American Journal of Veterinary Research 61: 1325-1332.

Finley, B.L., Monnot, A.D., Paustenbach, D.J. and Gaffney, S.H., 2012. Derivation of a chronic oral reference dose for cobalt. Regulatory Toxicology and Pharmacology 64: 491-503. https://doi.org/10.1016/j. yrtph.2012.08.022.

Fisher, J.W., 1959. The effects of cobalt injections on total circulating red cell volume and bone marrow cytology in normal and adrenalectomized dogs. Endocrinology 64: 522.

Gluhcheva, Y., Madzharova, M., Zhorovab, R., Atanasov, V., Ivanovac, J. and Mitewa, M., 2011. Cobalt(II)-induced changes in hemoglobin content and iron concentration in mice from different age groups. Biotechnology and Biotechnological Equipment 26: 126-128.

Hahn, G.J. and Meeker, W.Q., 1991. Distribution-free tolerance intervals and bounds to contain a specified percentage of a population. Statistical intervals: a guide for practitioners. WileyInterscience, New York, NY, USA, pp. 90-92.

Ho, E.N., Chan, G.H., Wan, T.S., Curl, P., Riggs, C.M., Hurley, M.J. and Sykes, D., 2015. Controlling the misuse of cobalt in horses. Drug Testing and Analysis 7: 21-30. https://doi.org/10.1002/dta.1719

Hoffmeister, T., Schwenke, D., Krug, O., Wachsmuth, N., Geyer, H., Thevis, M., Byrnes, W.C. and Schmidt, W.F.J., 2018. Effects of 3 weeks of oral low-dose cobalt on hemoglobin mass and aerobic performance. Frontiers in Physiology 9: 1289. https://doi. org/10.3389/fphys.2018.01289

Jelkmann, W. and Lundby, C., 2011. Blood doping and its detection. Blood 118: 2395-2404. https://doi.org/10.1182/ blood-2011-02-303271

Jitrapakdee, S., St. Maurice, M., Rayment, I., Cleland, W.W., Wallace, J.C. and Attwood, P.V., 2008. Structure, mechanism and regulation of pyruvate carboxylase. Biochemical Journal 413: 369-387.

Kearns, C.F., McKeever, K.H., 2002. Clenbuterol diminishes aerobic performance in horses. Medicine and Science in Sport and Exercise 34: 1976-1985.

Knych, H.K., Arthur, R.M., Mitchell, M.M., Holser, I., Poppenga, R., Smith, L.L., Helm, M.N., Sams, R.A. and Gaskill, C.L. 2015. Pharmacokinetics and selected pharmacodynamics of cobalt following a single intravenous administration to horses. Drug Testing and Analysis 7: 619-625.

Kobayashi, M. and Shimizu, S., 1999. Cobalt proteins. European Journal of Biochemistry 261: 1-9. 
Kubota, J., Welch, R.M., Van Campen, D., 1987. Soil related nutritional problem areas for grazing animals. In: Stewart, B.A. (ed.) Advances in soil science. Vol. 6. Springer-Verlag, New York, NY, USA.

Levine, B.D., 2008. $\dot{\mathrm{VO}}_{2 \max }$ : what do we know, and what do we still need to know? Journal of Physiology 586: 25-34.

Lippi, G., Franchini, M. and Guidi, G.C., 2005. Cobalt chloride administration in athletes: a new perspective in blood doping. British Journal of Sports Medicine 39: 872.

Lippi, G., Franchini, M. and Guidi, G.C., 2006. Blood doping by cobalt. Should we measure cobalt in athletes? Journal of Occupational Medicine and Toxicology 1: 18. https://doi.org/10.1186/1745-66731-18

Machin, J., Duer, W., Maylin, G., Fenger, C., Wilson, D., Ivey, M., Berthold, B., Allison, S. and Tobin, T., 2019. Variability in plasma concentrations of methylprednisolone 6 days after intrasynovial injection of methylprednisolone acetate in racing horses: a field study. Equine Veterinary Journal 51: 343-348. https://doi. org/10.1111/evj.13003

Mairbäurl, H., 2013. Red blood cells in sports: effects of exercise and training on oxygen supply by red blood cells. Frontiers in Physiology 4: 332. https://doi.org/10.3389/fphys.2013.00332

McKeever, K.H., Agans, J.M., Geiser, S., Lorimer, P. and Maylin, G.A., 2006. Low dose exogenous erythropoietin elicits an ergogenic effect in standardbred horses. Equine Veterinary Journal 36: 233-238.

McKeever, K.H., Eaton, T.L., Geiser, S., Kearns, C.F. and Lehnhard, R.A., 2010a. Aging related decreases in thermoregulation and cardiovascular function. Equine Veterinary Journal 42 (Suppl. 38): 220-227.

McKeever, K.H., Jarrett, S.H., Schurg, W.A. and Convertino, V.A., 1987. Exercise training-induced hypervolemia in the horse. Medicine and Science in Sports and Exercise 19: 21-27.

McKeever, K.H., Schurg, W.A. and Convertino, V.A., 1988. A modified Evans Blue dye method for the measurement of plasma volume in the horse. Journal of Equine Veterinary Science 8: 208-212.

McKeever, K.H., Wickler, S.J., Smith, T.R. and Poole, D.C., $2010 \mathrm{~b}$. Effects of high altitude and exercise on plasma erythropoietin in equids. Comparative Exercise Physiology 7: 193-199.

Persson, S., 1967. On blood volume and working capacity in horses. Studies of methodology and physiological and pathological variations. Acta Veterinaria Scandinavica Suppl. 19: 9-189.
R Core Team, 2014. Package 'KScorrect'. In: A language and environment for statistican computing. R Foundation for Statistical Computing, Vienna, Austria. Available at: http://www.r-project.org/ Robinson, N., Giraud, S., Saudan, C., Baume, N., Avois, L., Mangin, P. and Saugy, M., 2006. Erythropoietin and blood doping. British Journal of Sports Medicine 40, Suppl. 1: i30-i34. https://doi. org/10.1136/bjsm.2006.027532

Rose, R.J. and Hodgson, D.R., 1994. Hematology and biochemistry. In: Hodgson, D.R. and Rose, R.J. (eds.) The athletic horse: principles and practice of equine sports medicine. Saunders, Philadelphia, PA, USA, pp. 63-78.

Saxena, S., Shukla, D., Saxena, S., Khan, Y.A., Singh, M., Bansal, A., Sairam, M., Jain, S.K., 2010. Hypoxia preconditioning by cobalt chloride enhances endurance performance and protects skeletal muscles from exercise-induced oxidative damage in rats. Acta Physiologica 200: 249-263.

Thevis, M., Krug, O., Piper, T., Geyer, H. and Schänzer, W., 2016. Solutions advertised as erythropoiesis-stimulating products were found to contain undeclared cobalt and nickel species. International Journal of Sports Medicine 36: 82-84.

Toussaint, M., Fievez, L., Desmet, C.J., Pirottin, D., Farnir, F., Bureau, F. and Lekeux, P., 2012. Increased hypoxia-inducible factor $1 \alpha$ expression in lung cells of horses with recurrent airway obstruction. BMC Veterinary Research 8: 64. https://doi.org/10.1186/17466148-8-64

Unice, K.M., Monnot, A.D., Gaffney, S.H., Yvermoes, B.E., Thuett, K.A., Paustenbach, D.J. and Finley, B.L., 2012. Inorganic cobalt supplementation: prediction of cobalt levels in whole blood and urine using a biokinetic model. Food and Chemical Toxicology 50: 2456-2461.

Wenzel, R.G, Major, D., Hesp, K.F., Hall, E. and Doble, P., 2019. Cobalt accumulation in horses following repeated administration of cobalt chloride. Australian Veterinary Journal 97(11): 465-472. https://doi. org/10.1111/avj.12872

Zabrowska, M., Kucharski, J. and Wyszkowska, J., 2016. Biological activity of soil contaminated with cobalt, tin, and molybdenum. Environmental Monitoring and Assessment 188: 398. https://doi. org/10.1007/s10661-016-5399-8 